\title{
Pola Kunjungan Wisatawan Pada Daya Tarik Wisata Di Kawasan Sarbagita
}

I Putu Dody Andrian a, 1, Ida Bagus Suryawan a, 2

1 odyandrianputu@gmail.com, ${ }^{2}$ idabagussuryawan@unud.ac.id

a Program Studi Sarjana Destinasi Pariwisata, Fakultas Pariwisata,Universitas Udayana, Jl. Dr. R. Goris, Denpasar, Bali 80232 Indonesia

\section{Abstract}

In this research aims to the pattern of tourists' visit on tourists attraction in the area of Sarbagita. This reseach was carried out to find out the movement of tourists in visiting one to other tourist destinations which existed in the area of Sarbagita. This research was through several stages, namely: identification of characteristic of tourists who were visiting Sarbagita area and how about the pattern type of their visit. Next it was studying how the path of tourists' movement who were visiting tourist attractions existed in Sarbagita area. Data collection technique was using observation, interview, distribution of 100 questionnaires, literature study and documentation. Informant determination technique was using accidental sampling.

The result of research showed that tourists who were visiting various tourist destinations existed in Sarbagita area with the highest number of visits was in tourist attraction of Tanah Lot, Uluwatu, Kuta Beach, Sanur Beach, Bedugul, Ceking Rice Terrace and Pandawa Beach. The pattern of tourists' visit who were visiting Sarbagita area had 4 types of visits, namely the first wasm "Single Destination With or Without side Trips", the second was "Transit Leg and Circle Tour at a Destination", the third was "Circle Tour With or Without Multiple Access, Egress Points; Different Itinerary Styles Possible at Different Destination Areas", and the fourth was "Hub and Spoke Style".

\section{Keywords: Tourists, Pattern, Visit, Tourist Destination, Area}

\section{PENDAHULUAN}

Pulau Bali mempunyai bermacam daya tarik wisata antara lain; daya tarik wisata alami, daya tarik wisata ciptaan, dan daya tarik wisata kultural. Daya tarik wisata tersebut di kelola oleh pemerintah, masyarakat Bali, dan "Stakeholder". Pertumbuhan pariwisata di Bali meningkat dengan banyaknya perkembangan pilihan daya tarik wisata yang menjadi sajian untuk meningkatkan kunjungan wisatawan yang berkunjung ke Bali. Pertumbuhan kegiatan wisata pesatnya terjadi di wilayah Bali Selatan khususnya di wilayah kawasan Sarbagita.

"Menurut Peraturan Presiden Republik Indonesia No. 51 Tahun 2014 Tentang Perubahan Peraturan Republik Indonesia No. 45 Tahun 2011 Tentang Perencanaan Tata Ruang Kawasan Perkotaan Denpasar, Badung, Gianyar, Tabanan , yang selanjutnya disebut dengan Kawasan Kota Sarbagita." Kawasan Sarbagita merupakan kawasan yang terdiri dari kesatuan kawasan perkotaan diantaranya Kota Denpasa dan kawasan perkotaan Kuta yang merupakan kawasan perkotaan inti, kawasan perkotaan Mangupura dan kawasan perkotaan Jimbaran yang berada di Kabupaten Badung. Kawasan perkotaan Gianyar, kawasan perkotaan Sukawati dan kawasan perkotaan Ubud di Kabupaten Gianyar dan kawasan perkotaan Tabanan di Kabupaten Tabanan sebagai kawasan perkotaan sekitarnya dan membentuk kawasan metropolitan.

"Kawasan Sarbagita" mempunyai bermacam Daya Tarik Wisata unggulan yang ada di Bali. Daya tarik wisata tersebut memiliki kunjungan yang tinggi menurut data kunjungan wisatawan yang didapatkan dari Dinas Pariwisata Provinsi Bali diantaranya adalah daya tarik wisata Tanah Lot sebesar "3.524.335" wisatawan yang berkunjung. Pura Uluwatu sebesar "1.591.674" wisatawan yang berkunjung, Bedugul dengan jumlah kunjungan sebanyak “687.916”, Kebun Raya Bedugul dengan jumlah kunjungan sebanyak “570.055" , Tirta Empul dengan jumlah kunjungan sebanyak "524.647", Taman Ayun sebanyak "369.963", Goa Gajah dengan Jumlah kunjungan sebanyak "315.078" dan Badjra Sandhi Renon sebesar "251.438" wisatawan yang berkunjung.

Sarbagita adalah tempat atau destinasi berbagai atraksi wisata populer dengan besar jumlah wisatawan berkunjung baik dari wisatawan nusantara maupun mancanegara. Daya tarik wisata unggulan tersebut kebanyakan terdapat di kawasan Sarbagita, dan membuat kawasan Sarbagita menjadi kawasan inti pariwisata di pulau Bali. Maka dari itu dalam mengetahui pergerakan pola wisatawan dalam mengunjungi atraksi wisata yang ada di Kawasan Sarbagita. Bagaimana pola kunjungan 
dilakukan mereka pada atraksi wisata dikawasan Sarbagita dengan menentukan tipe pola kunjungan mereka dan bagaimana arah pergerakan mereka dalam melakukan kunjungan pada daya tarik wisata yang berada dikawasan Sarbagita.

\section{KEPUSTAKAAN}

Pada penelitian ini mengacu dalam penelitian sebelumnya diantaranya; Pertama, penelitain dilakukan oleh Putu Nanden Muliastini dan I Ketut Yadnyana Pada Tahun 2013 dengan judul "Pertimbangan Kinerja Pemerintah Kabupaten dan Kota Kawasan Metropolitan Sarbagita Tahun Anggaran 20072011". Penelitian kedua dilakukan oleh Fakih, dan Muhammad Fadli pada tahun 2006" dengan judul, "Penentuan Pola Kunjungan Wisatawan Ke Berbagai Objek Daya Tarik wisata di Pulau Ambon Menggunkan Metode Frequent Pattern Growth".

Konsep Tipe Pola Kunjungan (Mckercher dan Lew, 2014). Konsep Tipe Pola Kunjungan terdiri dari empat tipe kunjungan pertama yaitu pola tujuan tunggal, kedua pola tujuan dan melingkar, ketiga pola melingkar, dan ke empat pola pusat dan pola jari. Dalam penelitian ini konsep ini digunakan untuk menentukan bagaimana tipe pola kunjungan yang dilakukan oleh wisatawan dalam melakukan pergerakan kunjungan di kawasan Sarbagita.

\section{METODE PENELITIAN}

Penelitan ini dilakukan di tempat pusat perkumpulan para wisatawan yang ada di Bali yaitu Kawasan Kuta. Pusat wisata yang ada di Kawasan Sarbagita berada di Kuta yang merupakan kota kawasan inti pada Sarbagita. Kuta berada Desa Kuta, Kecamatan Kuta, Kabupaten Badung, Bali. Ruang lingkup dalam penelitian ini adalah menentukan tipe pola kunjungan yang dilakukan berdasarkan pola pergerakan wisatawan yang melakukan kunjungan ke berbagai daya tarik wisata di Kawasan Sarbagita. Penelitian ini menggunakan dua teknik pengumpulan sampel yaitu purposive sampling (Sugiyono, 2010) dan Accidental Sampling (Sugiyono, 2009). Purvosive sampling dalam penelitan ini digunakan dalam menentukan lokasi yang akan dijadikan tempat peneliatian yaitu Kuta sebagai tempat inti pariwisata di Kawasan Sarbagita. Accidental sampling dalam penelitian ini digunakan untuk menyebarkan kuesioner kepada para wisatawan ataupun responden. Dalam penelitian ini kuesioner yang terdapat sebanyak 17 pertanyaan dan 5 opsi tambahan, dalam setiap pertanyaan terdapat 5 opsi.

Penjumlahan :

$17 \times 5=85+12=\underline{97}$

dibulatkan menjadi 100

Jadi kuesioner yang di sebarkan kepada wisatawan atau responden sebanyak 100 kuesioner.

\section{HASIL DAN PEMBAHASAN}

Tipe Pola Kunjungan Wisatawan pada daya tarik Wisata di Kawasan Sabagita

Tipe pola tujuan tunggal didapatkan Kawasan Sarbagita.

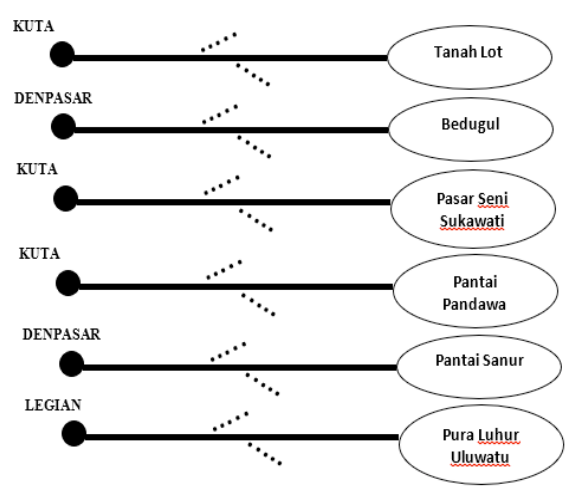

Gambar 1

"Pola Tujuan Tunggal"

Dari Gambar 1 dapat dijelaskan bahwa tipe pola kunjungan ini terjadi pada beberapa wisatawan yang berkunjung pada daya tarik wisata dikawasan Sarbagita. Dari gambar penelitian diatas dapat dijelaskan bahwa para wisata berada dari Kuta kunjungan langsung ke atraksi wisata yang berada di Tanah Lot balik lagi ke hotel para wisata yaitu di Kuta dan tidak lakukan berkunjung ke atraksi wisata yang lain. Dan kedua wisatawan dari Denpasar juga sama melakukan kunjungan di Bedugul dan balik lagi ke hotel mereka. Hal itu juga ditemukan di berbagai tipe pola kunjungan wisatawan lainnya seperti wisatawan dari Kuta ke Sukawati dan kembali lagi ke Kuta, wisatawan dari Kuta ke pantai Pandawa dan 
kembali ke Kuta, wisatawan dari Denpasar ke pantai Sanur dan kembali ke Sanur dan wisatawan dari Legian ke Pura Luhur Uluwatu dan kembali ke Legian tanpa melakukan kunjungan ke daya tarik wisata lainnya.

Tipe pola tujuan dan melingkar. Tipe ini terdapat pada wisatawan berkunjung pada atraksi wisata di Sarbagita.

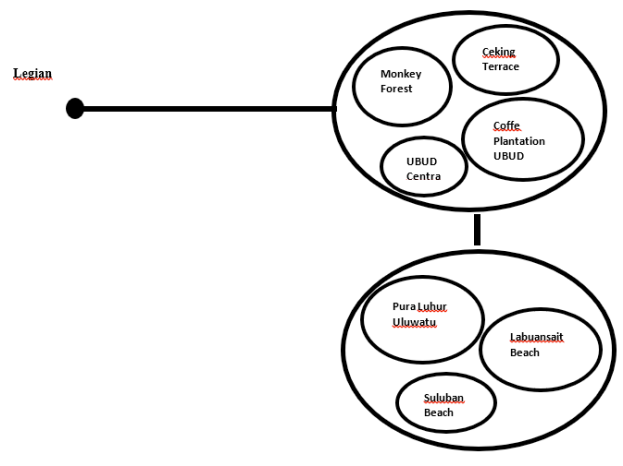

Gambar 2

"Pola Tujuan dan Melingkar"

Sumber: Penelitian Tahun 2017

Dari hasil gambar 2 dapat dijelaskan bahwa tipe ini adalah tipe pola kunjungan yang banyak ditemukan di pola kunjungan para wisata perkunjungan ke berbagai atraksi wisata di kawasan sarbagita. Pola ini merupakan kunjungan wisatawan dimana wisatawan menginap disuatu tempat dan melakukan kunjungan ke daya tarik wisata dan melakukan kunjungan kembali ke daya tarik wisata yang jarak nya tidak jauh dari daya tarik wisata sebelumnya yang sudah mereka kunjungi jadi kunjungan mereka melingkar diarea tempat destinasi wisata tersebut. Seperti gambar diatas kunjungan wisatawan yang dimana wisatawan tersebut menginap di Legian dan melakukan kunjungan ke Ubud dan melakukan kunjungan lagi ke daya tarik wisata di seputaran Ubud. Seperti mereka berkunjung kembali ke daya tarik wisata Monkey Forest lalu mereka berkunjung ke Ceking Terrace dan berkunjung ke Coffee Plantation Ubud dimana daya tarik wisata tersebut tidak berjauhan dari daya tarik wisata pertama yang mereka kunjungi selanjutnya mereka berpindah ke daya tarik wisata yang lain dan melakukan kunjungan melingkar disana seperti mengunjungi Pura Luhur uluwatu, pantai Labuan Sait, dan Pantai suluban yang area masih di kawasan wisata Uluwatu dan selanjutnya wisatawan tersebut kembali lagi ketempat mereka menginap di Legian.

Tipe pola ketiga adalah tipe pola melingkar (Circle Tour With Or Without Multiple Access, Egress Points ; Different Itinerary Styles Possible At Different Destination Areas).

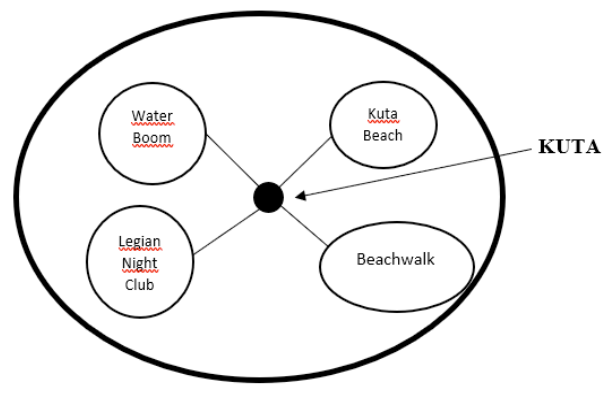

Gambar 3

"Pola Melingkar"

Sumber: Penelitian Tahun 2017

Berdasarkan gambar diatas dapat dijelaskan bahwa tipe pola melingkar merupakan tipe yang paling banyak ditemukan dalam tipe pola kunjungan wisatawan di kawasan Sarbagita berkisaran 65\% wisatawan dari 100 responden yang memiliki pola kunjungan tersebut. Pola kunjungan ini paling banyak terjadi di kawasan tempat wisatawan menginap yaitu di kawasan Kuta. Seperti pada gambar diatas wisatawan yang Menginap di Kuta cenderung memilih untuk melakukan liburan pada atraksi wisata yang di Seputaran tempat para wisata menginap. Dimana para wisata di Kuta memilih berlibur di wisata Waterboom, Kuta Beach, Legian Night Club, dan Mall seperti Beach Walk atau Centro Departement Store. Dimana daya tarik wisata tersebut masih dalam cakupan kawasan pariwisata Kuta tanpa melakukan kunjungan keluar dari wilayah tersebut sampai wisatawan tersebut kembali lagi ke tempat asal mereka. Atau bisa dijelaskan wisatawan tersebut hanya melakukan kunjungan di seputaran kawasan Kuta selama mereka menghabiskan waktu liburan mereka di kawasan sarbagita.

Tipe keempat merupakan tipe pola kunjungan yaitu pola pusat dan pola jari $\mathrm{Hub}$ 
And Spoke). Tipe keempat ini merupakan tipe pola kunjungan yang berpindah-pindah atau wisatawan tidak hanya menginap di satu tempat destinasi tetapi mereka menginap lebih dari satu tempat destinasi yang memiliki daya tarik wisata di dalam tempat area mereka menginap.

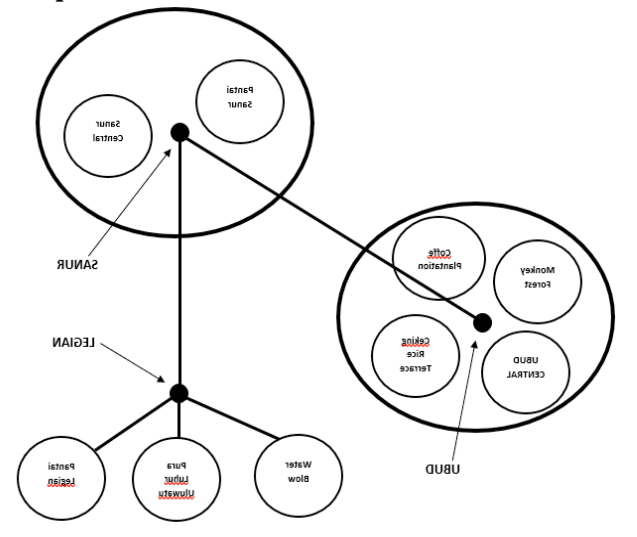

Gambar 4

Pola Pusat dan Pola Jari

\section{Sumber: Penelitian Tahun 2017}

Berdasarkan gambar 4 dapat dijelaskan bahwa wisatawan yang mempunyai tipe kunjungan seperti ini merupakan wisatawan yang memiliki waktu kunjungan yang lama ke tempat destinasi wisata. Dalam penelitian ini wisatawan yang memiliki kunjungan tipe seperti ini mereka berada dikawasan Sarbagita bisa mencapi 3 minggu sampai 1 bulan ataupun lebih. Dari gambar diatas dapat di jelaskan bahwa wisatawan tersebut pertama kali menginap di Sanur dan melakukan kunjungan di seputaran Sanur seperti pantai Sanur dan kawasan area Sanur. Selanjutnya mereka berpindah tempat dan menginap di Ubud dan melakukan kunjungan pada daya tarik wisata disana seperti mengunjungi daya tarik wisata Monkey Forest, Ubud Central, Coffee Plantation Ubud dan kawasan pura-pura di Ubud. Selanjutnya terakhir mereka menginap di Legian tetapi pola kunjungan mereka berbeda, dimana wisatawan tersebut melakukan tipe pola kunjungan langsung ke daya tarik wisata yang mereka tuju seperti daya tarik wisata Pura Luhur Uluwatu, Pantai Legian dan waterblow. Tipe kunjungan ini merupakan tipe yang paling sedikit yang ditemukan pada pola kunjungan wisatawan yang melakukan kunjungan di kawasan Sarbagita.

\section{PENUTUP}

\section{Simpulan}

Sarbagita adalah Kawasan perkotaan yang di antaranya meliputi "Denpasar", "Badung", "Gianyar" dan "Tabanan" dan kemudian disebutkan sebagai "Kawasan Sarbagita". Ada beberapa tipe yang ditemukan di "kawasan sarbagita" diantaranya empat pola yaitu pertama tipe pola kunjungan tujuan tunggal, kedua tipe pola tujuan tunggal dan melingkar, ketiga tipe pola melingkar, dan keempat tipe pola pusat dan jari.

\section{Saran}

Berdasarkan kesimpulan tersebut, saran yang dapat disimpulkan dari hasil penelitian diantaranya ; Kawasan Sarbagita adalah tempat dari berbagai daya tarik wisata unggal yang ada di Bali, diperlukan fasilitas umum yaitu transportasi umum yang mempermudahkan wisatawan dalam mencapai tujuan mereka pada daya tarik wisata yang akan mereka kunjungi dan Kemacetan perlunya ditanggulangi agar wisatawan nyaman dalam melakukan perjalanan ke daya tarik wisata yang mereka tuju dan mempercepat jarak tempuh tujuan mereka pada daya tarik wisata di Kawasan Sarbagita.

\section{DAFTAR PUSTAKA}

Anonim, 2009. "Undang - Undang Republik Indonesia No. 10 Tahun 2009 Tentang Kepariwisataan".

Anomin, 2011. "Peraturan Presiden Republik Indonesia No. 45 Tahun 2011 Tentang Rencana Tata Ruang Kawasan Perkotaan Denpasar, Badung, Gianyar dan Tabanan".

Anomin, 2014. "Menurut Peraturan Presiden Republik Indonesia No. 51 Tahun 2014 Tentang Perubahan Peraturan Presiden Republik Indonesia No. 45 Tahun 2011 Tentang Rencana Tata Ruang Kawasan Perkotaan Denpasar, Badung, Gianyar dan Tabanan."

Bob McKercher, Gigi Lau, 2008. "Movement Patterns of Tourists Within a Destination". Tourism Geographies: An International Jurnal of Tourism Space, Palce and Environment.

McKercher, dan Lew, 2004. Tourist Flow And The Spatial Distribution Of Tourists. Dalam : Parroco, A. M., et. al. (2011). Multi-Destination Trip Behaviours: Methodological Issues and the Research Design of a Survey on Incoming Tourism in Sicily.

Sugiyono, 2009. "Metode Penelitian Bisnis, Pendekatan Kuantitatif, Kualitatif dan R\&D”. Bandung : Alfabeta

Sugiyono. 2010. "Metode Penelitian Pendidikan Pendekatan Kuantitaf, Kualitatif, dan R\&D". Bandung : Alfabeta 